\title{
RELATIONSHIP BETWEEN COMPACTING PRESSURE AND CONDITIONS IN PRESSING CHAMBER DURING BIOMASS PRESSING
}

\author{
Peter Križan*, Miloš Matúšs, Juraj Beniak \\ Institute of Manufacturing Systems, Environmental Technology and Quality Management, Faculty of \\ Mechanical Engineering STU in Bratislava, Nám. Slobody 17, 81231 Bratislava, Slovakia \\ * corresponding author: peter.krizan@stuba.sk
}

\begin{abstract}
In this paper, we will present the impact of the conditions in pressing chambers during the pressing of wooden briquettes. The conditions in pressing chambers can significantly impact the resulting compacting pressure required for the pressing of briquettes. In the introduction, we show which parameters of the pressing chamber during pressing can impact the resulting compacting pressure. The experiment results which are shown in this paper described the detected impact of some important pressing chamber parameters. This experiment aims to detect the pressing chamber length impact and the impact of the way of pressing. By setting the pressing conditions, we will be able to achieve the suitable resulting compacting pressure with respect to the required final briquettes quality.
\end{abstract}

KEYWORDS: biomass; briquetting; pressing chamber length; compacting pressure; pressing way; briquette density.

\section{INTRODUCTION}

Biomass densification process, as a production process of solid biofuels from biomass is very important level of waste biomass energy recovery [1]. It is also one of the most interesting and most complicated biomass treatment processes. The result of the densification process, the briquette, is assessed and defined according to international standards - EU standards, and is evaluated by mechanical and chemical-thermic indicators. Solid biofuels are produced by densification machines, most usually from wood wastes (chips, pieces of wood waste, sawdust, topwood, etc.). If we use solid biofuels with accumulated energy values, the combustion process is as effective as burning a piece of wood waste. At the present time we know many producers of densification machines with a wide range of machines. However, not every machine can produce biofuels (briquettes or pellets) that meets the required quality standards. This fact demonstrates the many problems which have to be solved. The properties of the pressed material, as well as technological demands, are both very important for the briquette production process. The input material needs to be reduced to the optimal particle size, dried to the optimal moisture content level, and we have to provide optimal technological parameters throughout the process of densification [2]. Every type of material requires an independent approach. Each small change in the properties of the input materials can influence the final quality of the briquette. Different material properties cause different conditions during the densification process 6.

The same applies when we talk about the effect of influencing parameters during the densification pro- cess. The final quality of the briquette is influenced by many parameters. On the basis of the experience that we have acquired and of the analyses that we have made, we can divide the parameters into the following three groups [3, 5, 6]: material parameters; structural parameters; technological parameters. The material parameters emerge from the properties of the pressed material. After carrying out analyses in our institute we know that the final briquette quality is significantly affected by the chemical composition of the material, its density, its moisture content, the material contexture and the structure, which is shown mainly by the size of the chips. During the biomass densification we can also identify other types of parameters which are influencing the final briquette quality. The technological parameters deal with the parameters of densification technology and the structural parameters are related to the pressing chamber. It is necessary to understand the pressing process itself - densification, pressure distribution within the chamber, effects of chamber geometry on the pressure distribution. Based on this knowledge we can effectively describe the effects occurring within the pressing chamber during compaction, and the resulting behaviour of the material.

Because one of the goals was to determine the effect of important structural parameters during densification, it was necessary to perform an analysis of existing mathematical models or to study the current state in this field. After carrying out analyses, when we used research findings [11-17], we can understand that not many mathematical models describe the densification process precisely. No one describes the densification process related to the final briquette quality. The descriptions that do exist are based on pressing the- 


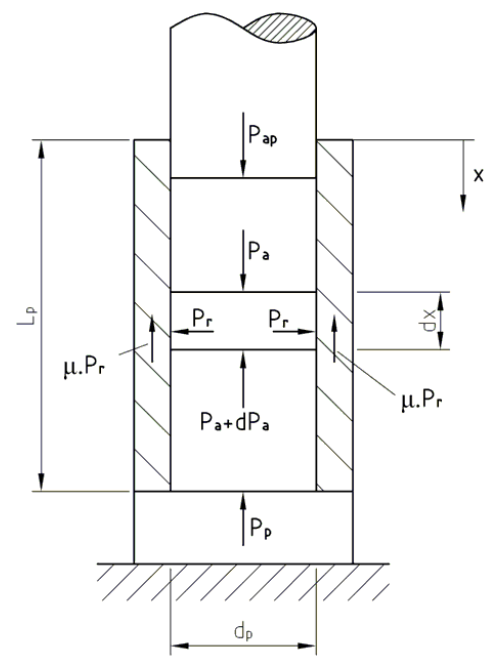

Figure 1. Pressing conditions in closed pressing chamber by single-axis pressing on vertical press [2, 7, 8.

ory and describe the pressure ratio throughout the pressing process. That is not to say that the models are useful. They can be used in the design of the pressing chamber, or the formulation of a mathematical model, which will describe the effects of structural parameters on the resulting briquette quality. However, models describing the effects of changing structural parameters on the pressing process and the effects of the pressed material do not exist. It is very important to find a relationship between the density of the briquette and selected structural parameters. These relationships provide an excellent foundation when designing pressing machines (chambers). Due to these reasons, several experiments were executed on our department. In this contribution we would like to describe the conditions in the pressing chamber during pressing and also the parameters which influence these conditions.

\section{MAterials AND METHODS}

On the basis of our knowledge and experiences from executed measurements we can identify the impact of technological parameters (compacting pressure, pressing temperature) and the impact of pressed material parameters (type of raw material, moisture content and fraction size) on briquette density. The structural parameters which significantly influence the final briquette density are the length of the pressing chamber, the diameter of the pressing chamber, the conicalness of the pressing chamber, the friction coefficient between the chamber and pressed material, pressing speed, etc. [4. With a suitable combination of the mentioned parameters we can significantly impact the densification process, mainly from the final briquette quality point of view. We will be able to find the optimal conditions for each specific input setting (type of material and its parameters).
In this paper we would like to present research findings which describe the impact of pressing chamber length and the role of this parameter at densification. The results presented in this paper deal only with single-axis pressing in cylindrically shaped pressing chambers.

On the basis of single-axis pressing theory in closed chambers we can analyze the impact of changes in the length of the pressing chamber. The diameter of the pressing chamber with the length of the pressing chamber has a significant impact on briquette properties at briquette burning and also on pressing tool wearing. It is related to the briquette surface to volume ratio. The pressing conditions in a closed chamber at single-axis pressing when the counter pressure is generated by the counter pressure plug is shown in Figure 1. The axial compacting pressure acting on the briquette $P_{a}$ at pressing depends on:

- axial compacting pressure $P_{a p}$;

- pressing chamber length and shape;

- friction relations between pressed material and wall of the chamber.

The drag friction is backward assigned by radial pressure $P_{r}$, applied to the chamber wall, by friction coefficient $\mu$, and length of pressed briquette $L_{p}$. The following equations [1, 2] describe Figure 1].

$$
\begin{gathered}
\left(P_{p}-\left(P_{p}+d P_{p}\right)\right) \frac{\pi d_{p}^{2}}{5}-\mu P_{r} \pi d_{p} d x=0 \\
P_{a p}=P_{p} e^{4 \lambda \mu L_{p} / d_{p}}(\mathrm{MPa})
\end{gathered}
$$

where $P_{a} p$ is the axial compacting pressure of dressing piston $(\mathrm{MPa}) ; P_{r}$ is the radial pressure $(\mathrm{MPa}) ; P_{p}$ is the counter pressure in pressing chamber $(\mathrm{MPa}) ; P_{a}$ is the axial pressure on briquette $(\mathrm{MPa}) ; d_{p}$ is the diameter of dressing chamber $(\mathrm{mm}) ; \mu$ is the fiction coefficient $(-) ; L_{p}$ is the length of pressing chamber (mm).

By solving equation (1) and by substituting the border conditions, we obtained equation (2). Equation (1) specifies the relation between axial pressure $P_{a p}$ and the counter pressure effecting on pressed briquette $P_{p}$. This mathematical model was designed by German researchers W. Horrighs, K. Kegel, H., Rumpf [2, 9, 10, 12, and it describes densification on the vertical press. The model can also be used to describe the effecting forces and pressures in the pressing chamber. With this mathematical model, we were able to simulate the impact of chosen structural parameters. We tried to test the impact of length of the pressed briquette, and these results can be used calculate the optimal length of the pressing chamber. By testing we chose unit values for other parameters in the model and step by step we raised the value of the length of the pressed briquette, always by about $10 \%$. You can see this in Figure 2 You can see that with an increase in the pressing chamber length, the acting axial pressure on the pressed briquette also 


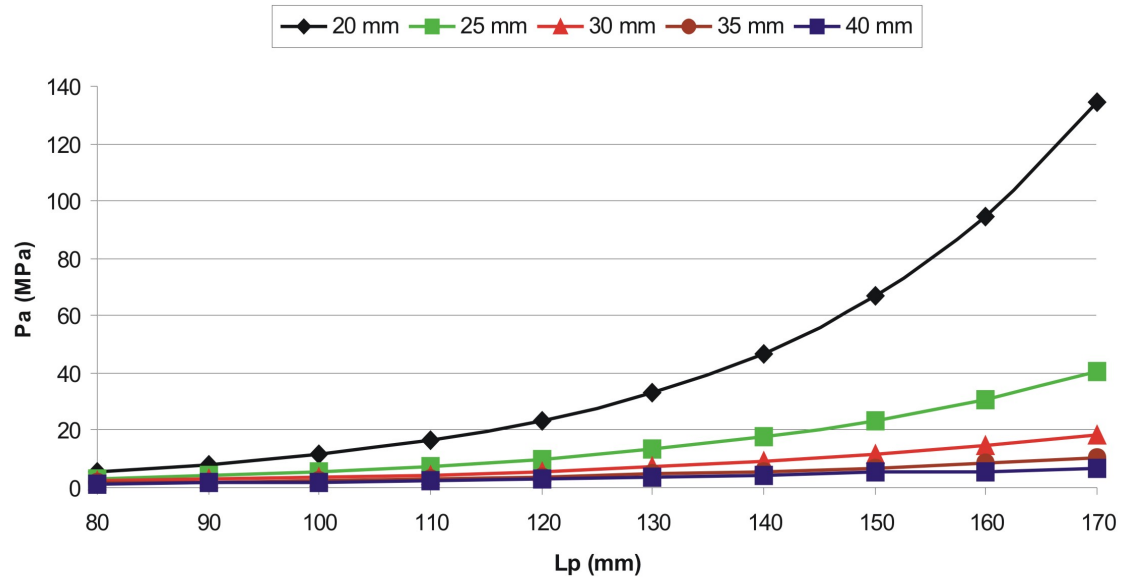

Figure 2. Dependence of axial pressure $P_{a}$ on pressing chamber length Lp at varying pressing chamber diameter $d_{p}$ [3, 4.

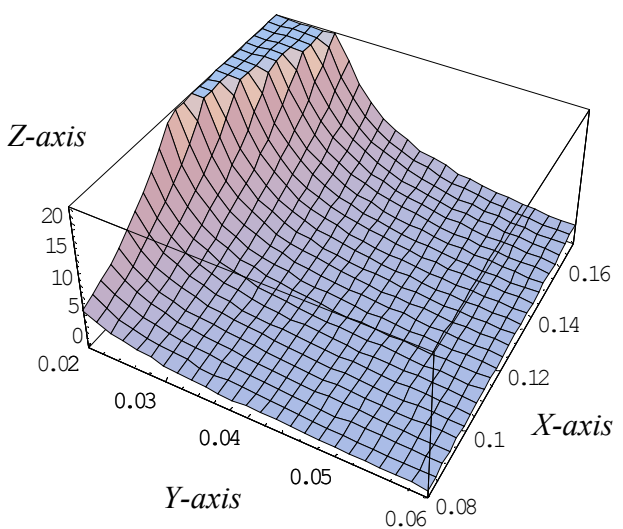

Figure 3. Dependence of axial pressure $P_{a}$ on length of pressing chamber $L_{p}$ and pressing chamber diameter $d_{p}$ (at constant friction coefficient $\mu=0.4$ ) [4, 6]. Here $x$-axis represents the pressing chamber length (m); $y$-axis represents the pressing chamber diameter (m); $z$-axis represents the axial pressure on briquette (MPa).

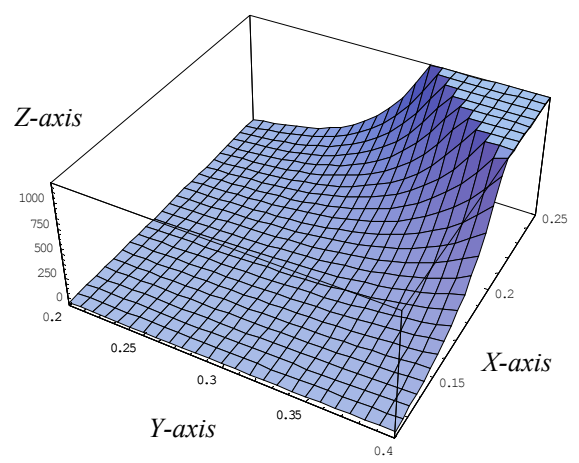

Figure 4. Dependence of axial pressure $P_{a}$ on length of pressing chamber $L_{p}$ and friction coefficient $\mu$ (at constant pressing chamber diameter $d_{p}=20 \mathrm{~mm}$ ) [4, 6]. Here $x$-axis represents the pressing chamber length $(\mathrm{m}) ; y$-axis represents the friction coefficient $(-) ; z$-axis represents the axial pressure on briquette $(\mathrm{MPa})$.
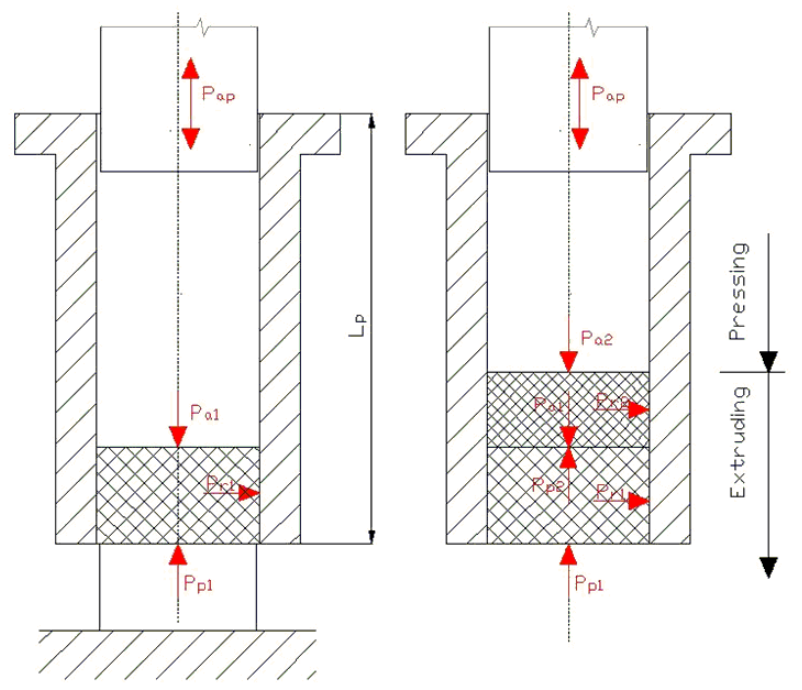

Figure 5. Behaviour of acting pressures in experimental pressing stend, which represents the vertical pressing way [3].

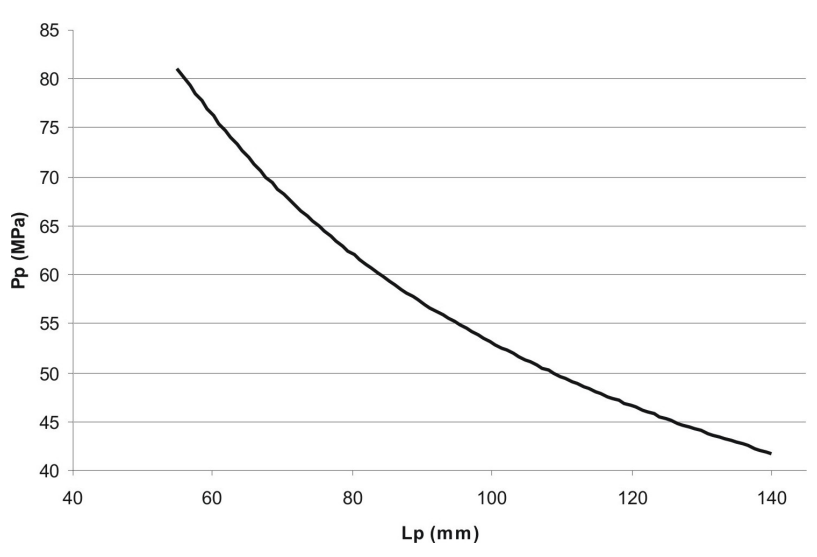

FiguRE 6. Dependence of counter pressure $P_{p}$ on pressing chamber length $L_{p}$ at $20 \mathrm{~mm}$ pressing chamber diameter $[3]$. 


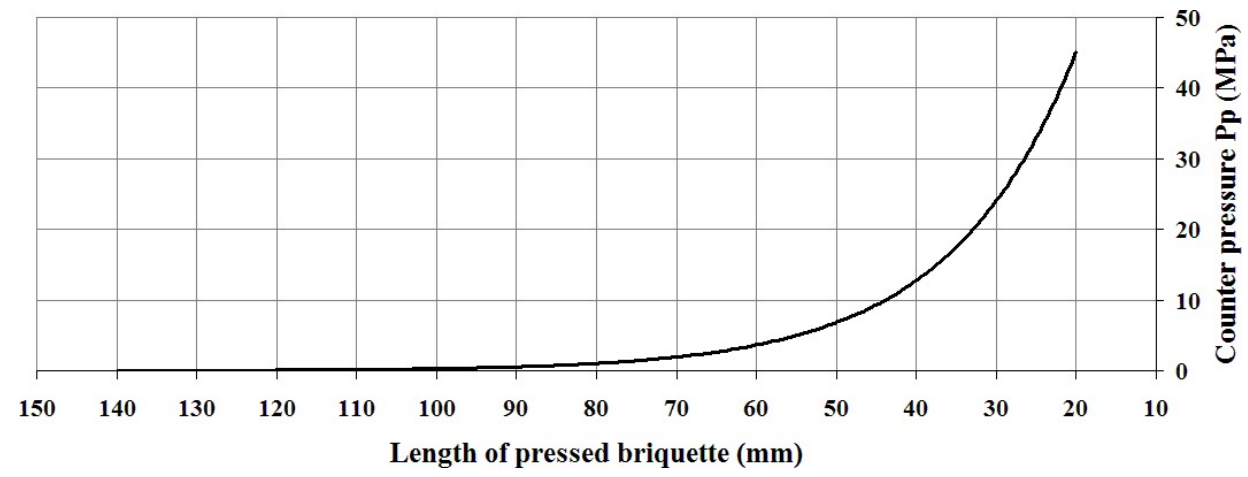

FiguRE 7. Dependence of counter pressure $P_{p}$ on length of pressed briquette $[5]$.

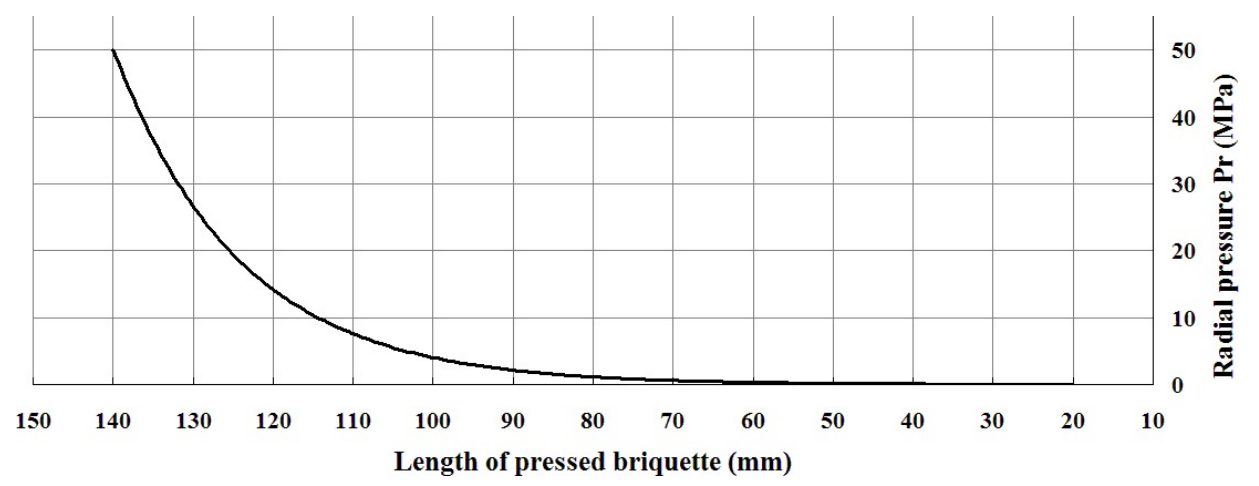

Figure 8. Dependence of radial pressure $P_{r}$ on length of pressed briquette [5].

increases. The value of increasing of course depends on the pressing chamber diameter. This simulation using the Mathematics computer software was done and was executed only for confirming the above-mentioned parameter effect. For this simulation, the following value levels were selected for each parameter: diameter of the pressing chamber $d_{p}=20-60 \mathrm{~mm}$; friction coefficient $\mu$ for steel-wood friction pair was chosen from $0.1-0.4$. The axial pressure on briquette $P_{a}$ was calculated.

The impact of pressing chamber length is obvious on the basis of mathematical analysis. We wanted to verify this assumption by experiment on an experimental pressing stend. During this experiment we wanted to measure the impact by decreasing the pressing chamber length. When we designed the simulation and experiment we were limited by the dimensions of the experimental pressing stend. A change in the pressing chamber influences the behavior of the axial pressure on briquette $P_{a}$. This pressure influences the final strength and density of the briquettes. Through theoretical analysis we found that with an increase in the pressing chamber length, the axial pressure on briquette $P_{a}$ also increases.

Knowledge of the acting radial pressure and counter pressure is very important during pressing. The counter pressure avoids to leave the raw material the pressing chamber before densification and helps with briquette densification. The counter pressure value with the value of radial pressure influence the length of the pressing chamber. The designed mathematical model (2) can be used for simulation and calculation of these types of pressure.

During the pressing of bulk material, the lonely process is mostly based on pressure anisotropy - it means that there are higher pressures in the perpendicular direction. The ratio of main strains $\sigma_{r} / \sigma_{a}$ is called horizontal pressing ratio $\lambda$. For dispersive materials, this ratio reaches values $0<\lambda<1$. For each briquette in the pressing chamber, $P_{p}=P_{a}[8]$. On the basis of Figure 1 and (2) we can calculate the radial pressure $P_{r}$ or counter pressure $P_{p}$ from the following equation [2]:

$$
\lambda=\frac{\sigma_{r}}{\sigma_{a}}=\frac{P_{r}}{P_{a}}=\frac{P_{r}}{P_{p}}, \text { hence } P_{r}=\lambda P_{p}(\mathrm{MPa}) .
$$

The result can be seen in Figure 6. For this calculation we used the real dimensions of the experimental pressing stend (diameter $20 \mathrm{~mm}$, length $60-140 \mathrm{~mm}$ ).

If we transform these result and knowledge to a horizontal pressing way and preserve the pressing stend dimensions, we are able to obtain the following dependencies. It is necessary to say that in this calculation the pressing chamber length was replaced by the length of the pressed briquette. This substitution comes from the fact that during pressing in an "open called chamber", the length of the pressed briquette in the pressing chamber represents the pressing chamber length.

Previous dependencies have to explain that the zero point of the y-axis represents the beginning level of pressing (from the pressing piston side). The opposite side $(140 \mathrm{~mm})$ represents the end of the chamber, 


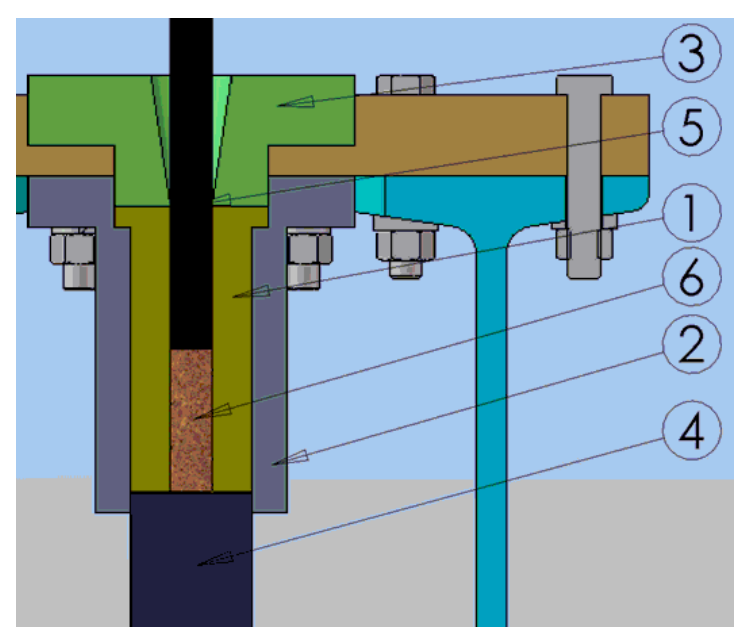

Figure 9. Cross-view of experimental pressing stend (1-pressing chamber; 2-pressing chamber flange; 3 - start-up chamber; 4 - counter pressure plug; 5pressing piston; 6-pressed material).

behind this level briquette leaves the chamber. This result shows that the pressing chamber length or the length of the pressed briquette significantly influences the conditions in the pressing chamber during pressing.

\section{EXPERIMENT AND RESULTS}

The briquettes were produced using a vertical hydraulic press which was modified with the use of an experimental pressing stand (see Figures 9 and 10 . The experimental pressing stand consists of a base frame, a cylindrical pressing chamber with a $20 \mathrm{~mm}$ diameter die, a heating device with a temperature sensor for temperature control, and the backpressure plug. We were limited by stend dimensions and therefore we decided to perform the experiment only with the three lengths of the pressing chamber $(100,120$ and $140 \mathrm{~mm}$ ). In Figures 9 and 10 you can see the pressing stend cross-section. The pressing chambers with the various lengths was gradually changed during the experiment and for each chamber 95, 127 and $159 \mathrm{MPa}$ compacting pressure levels were used. The pressing procedure consisted in pressing 3 briquettes without releasing the counter pressure plug. After that, the briquettes left the stend, which means that they were extruded from the pressing chamber. A vertical hydraulic press can determine the executed or the final value of acting pressure. It means that the value of the acting pressure from the press control panel was visible and readable.

The goal of the research was to identify the impact of the pressing chamber length on the final briquettes quality. The dependencies in Figures 11 and 12 represent the pressing with various pressing chamber lengths. You can see that with an increase in compacting pressure the final briquette density also increases. The change in the pressing chamber length

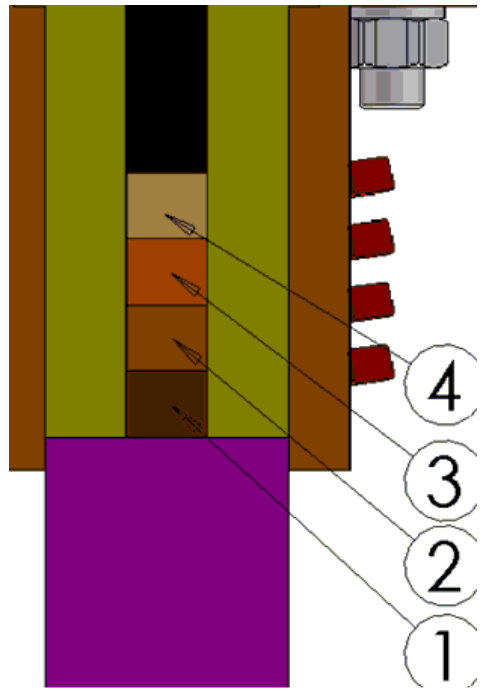

Figure 10. Process of briquette pressing (the number represents the position and quantity of briquettes).

also positively impacts the final briquette density.

During the experiment we tried to monitor the acting axial pressure in the pressing chamber. In Figure 13 you can see the behavior of the acting pressure during pressing. This figure shows the pressing process which represents step-by-step pressing of 3 briquettes and their releasing out of the chamber. We can also see the releasing pressure which depends on axial pressure (in this case $95 \mathrm{MPa}$ ) and on length of the pressed briquette. We can also notice the placement exactly where the pressure is acting in the chamber.

In Figure 14 we can see a closer view of the releasing pressure. This pressure depends on the axial pressure which was used for briquette pressing. In this figure we can see the differences between releasing pressure values depending on different axial pressures.

Figures 15 and 16 describe a similar releasing pressure behavior but in pressing chambers with various lengths (120 and $100 \mathrm{~mm}$ ). We can notice different values of releasing pressures and also different pressure behavior in different placements in the chamber.

\section{Conclusions}

These results prove that the conditions in pressing chambers during pressing depend also on the pressing chamber length. With this experiment we confirmed the assumption that pressing chamber length influences the final briquette density and also the radial pressure acting in the pressing chamber. We were able to indirectly measure the radial pressure through the pressure for briquette releasing. This result is sufficiently valid and was also measured at constant friction coefficient. It means that during the experiment we provided constant values of material moisture, material fraction size, pressing temperature and all pressing chambers were produced from the same type of steel (14220) with equal surface roughness. 


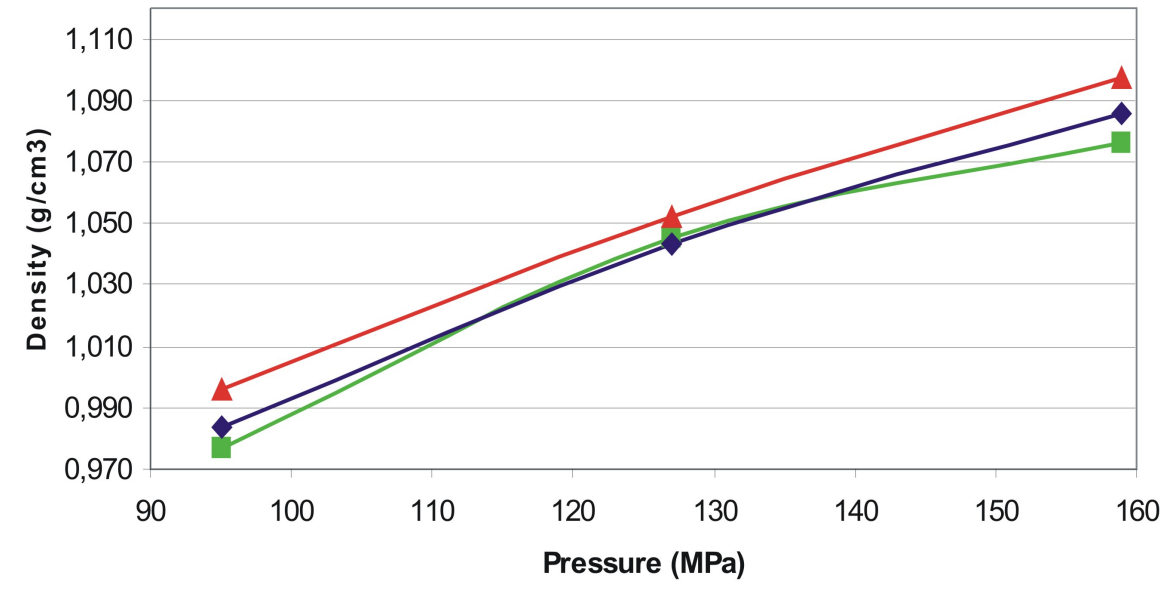

$\neg-\operatorname{Lp} 100 \multimap \operatorname{Lp} 120 \multimap-\operatorname{Lp} 140$

FIGURE 11. Dependence of briquette density on compacting pressure at various lengths of pressing chamber $\left(L_{p}\right)$.

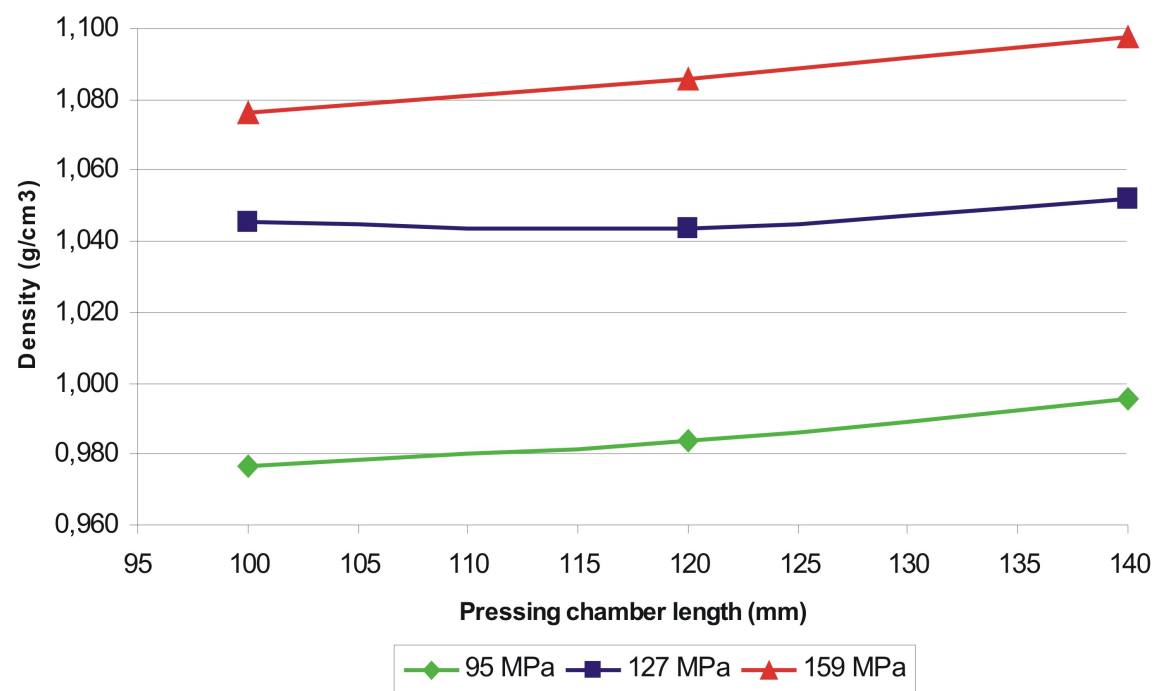

Figure 12. Dependence of briquette density on pressing chamber length $\left(L_{p}\right)$ at different compacting pressures.

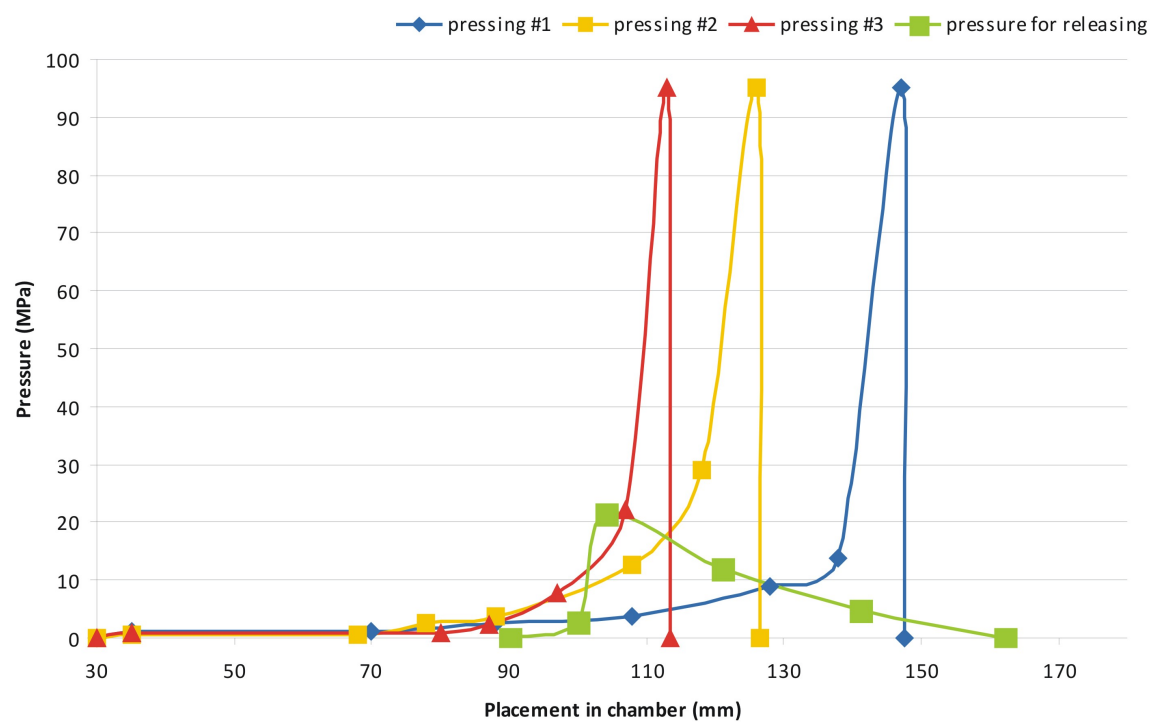

FigURE 13. Dependence of acting pressure on piston stroke (placement in chamber) during pressing in $140 \mathrm{~mm}$ chamber at $95 \mathrm{MPa}$. 


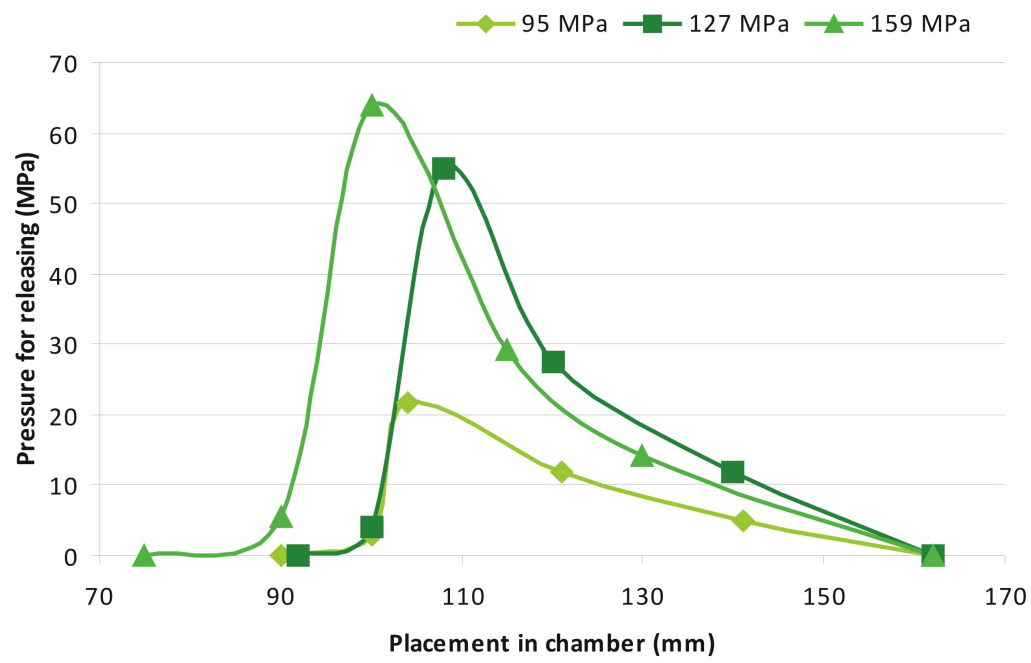

FiguRE 14. Dependence of pressure for briquette releasing on piston stroke (placement in chamber) during pressing in $140 \mathrm{~mm}$ at various axial pressures.

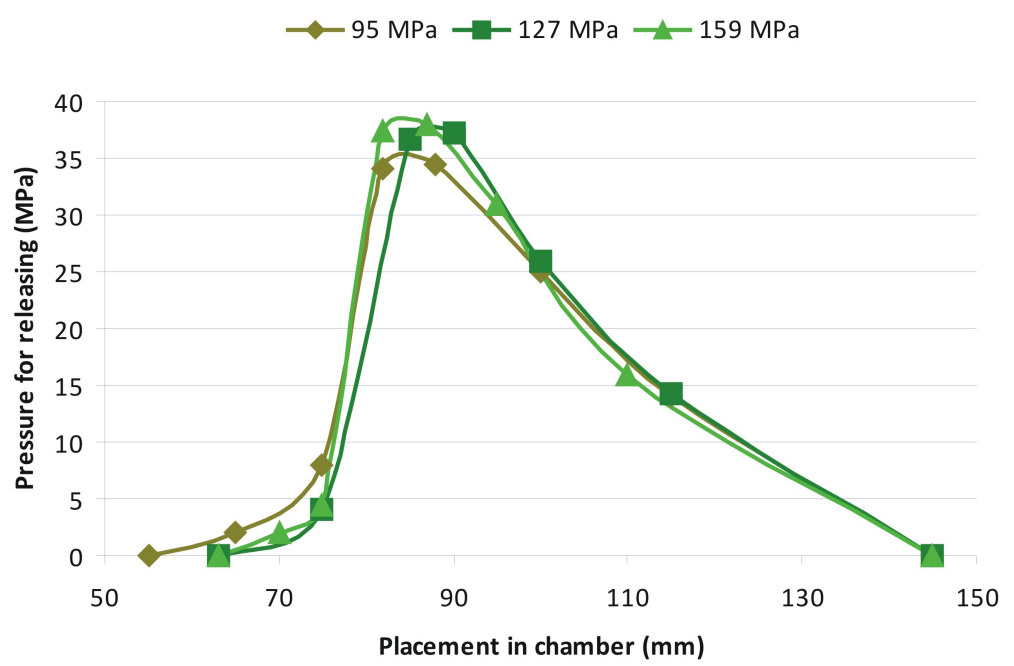

FiguRE 15. Dependence of pressure for briquette releasing on piston stroke (placement in chamber) during pressing in $120 \mathrm{~mm}$ at various axial pressures.

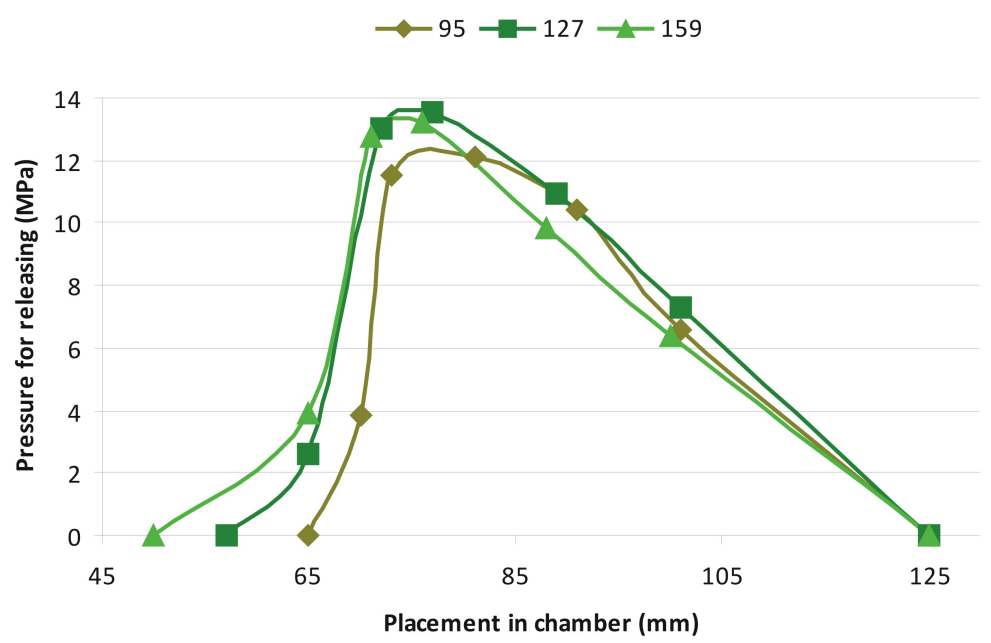

FIGURE 16. Dependence of pressure for briquette releasing on piston stroke (placement in chamber) during pressing in $100 \mathrm{~mm}$ at various axial pressures. 


\section{ACKNOWLEDGEMENTS}

The research presented in this paper is an outcome of the project APVV-0857-12 "Tools durability research of progressive compacting machine design and development of adaptive control for compaction process" funded by the Slovak Research and Development Agency.

\section{REFERENCES}

[1] Moskalík, J., Škvařil, J., Štelc, O., Baláš, M., Lisý, M.: Energy recovery from contaminated biomass. - In:Acta Polytechnica, ISSN 1210-2709. - Vol. 52, No.3 (2012), pp. $77-82$.

[2] Holm, J.; Henriksen, U.; Hustad, J.; Sorensen, L.: Toward an understanding of controlling parameters in softwood and hardwood pellets production, American Chemical Society, published on web 09/09/2006.

[3] Križan, P.; Vukelič, Dj.: Shape of pressing chamber for wood biomass compacting. In: International Journal for Quality Research. - ISSN 1800-6450. - Vol. 2, No. 3 (2008), p. 205-209

[4] Križan, P.; Matúš, M.; Kers, J.; Vukelič, Dj.: Change of pressing chamber conicalness at briquetting process in briquetting machine pressing chamber. In: Acta Polytechnica. - ISSN 1210-2709. - Vol. 52, No. 3 (2012), p. $60-65$

[5] Križan, P.; Šooš, L.; Matúš, M.: Optimalisation of briquetting machine pressing chamber geometry. In: Machine Design. - ISSN 1821-1259. - 2010. - , 2010, pp. 19-24

[6] Matúš, M.; Križan, P.: Influence of structural parameters in compacting process on quality of biomass pressing. In: Aplimat - Journal of Applied Mathematics. - ISSN 1337-6365. - Vol. 3, No. 3 (2010), p. 87-96

[7] Horrighs, W.: Control of ram extruders for obtaining steady compaction pressures. Journal for preparation and processing Aufbereitungs-Technik, nr. 7/1987, Wiesbaden, 1987, ISSN 0004-783 X, p. 378-382
[8] Horrighs, W.: Determining the dimensions of extrusion presses with parallel-wall die channel for the compaction and conveying of bulk solids, Journal for preparation and processing Aufbereitungs-Technik, nr. 12/1985, Wiesbaden, 1985, ISSN 0004-783 X, p. 724-732

[9] Kegel, K.: BriketierHandbuch, Halle (Saale), Verlag von Wilhelm Knapp, 1948

[10] Rumpf, H.: Die Wissenschaft des Agglomerierens, Chemie-Ingenieur-Technik (1974), Nr.1, pp. 1-11

[11] Ivanova, T.; Muntean, A.; Havrland, B; Pobedinsky, V.: Theoretical modeling of the briquetting process with different pressing equipment. In: Agronomy Research. ISSN 1406-894X. - Vol. 11, No. 1 (2013), pp. 47-52

[12] Horrighs, W.: The Dimensioning of an Extrusion Press. In: Powder Technology. - ISSN 0032-5910. - Vol. 56, No. 1 (1988), pp. $13-20$

[13] Johnson, R. E.: Conical extrusion of a work-hardening material: an asymptotic analysis. ISSN 0022-0833. - Vol. 21, No. 4 (1987), pp. 295-329, DOI:10.1007/BF00132681

[14] Malujda, I.: Plastic Yield of Particulate Materials under the Effect of Temperature. - Chapter. Progress in Industrial Mathematics at ECMI 2008, Vol. 15 of the series Mathematics in Industry, 2010, ISBN 978-3-642-12109-8. - pp. 939-944, DOI:10.1007/978-3-642-12110-4_150

[15] Generalov, M. B.; Zubkov, V. A.; Popov, Yu. P.: Design of the conical annular section of extrusion heads. - ISSN 0009-2355. - Vol. 5, No. 3 (1969), pp. 204-207, DOI:10.1007/BF01137115

[16] Muntean, A.; Havrland, B.; Pobedinsky, V.; Ivanova, T.; Grigore, M.: Features of bio-briquettes pressing with the piston briquetting press. - In: Proceedings of 9th International Scientific Conference - Enginiering for Rural Development. 27.-28.05.2010, Jelgava, Latvia, ISSN 1691-5976, pp. $246-251$

[17] Nazarov, V.I.; Bulatov, I.A.; Makarenkov, D.A.: Features of the development of extrusion granulation of biofuel based on wood and plant waste products. In: Chemical and Petroleum Engineering. - ISSN 0009-2355. - Vol. 45, No. 1 (2009), pp. 96-104, DOI:10.1007/s10556-009-9132-0 